\title{
A Process for the Preparation of Chitin and Chitosan from Prawn Shell Waste
}

\author{
F. Nessa ${ }^{a *}$, Shah Md. Masum ${ }^{b}$, M. Asaduzzamana , S. K. Roy \\ M. M. Hossain ${ }^{\mathrm{a}}$ and M. S. Jahan ${ }^{\mathrm{c}}$ \\ ${ }^{a}$ Chemical Research Division, BCSIR Laboratories, Dhaka-1205, ${ }^{b}$ Department of Applied Chemistry and \\ Chemical Engineering, University of Dhaka, Dhaka-1000, 'Paper and Pulp Research Division, BCSIR \\ Laboratories, Dhaka-1205.
}

\begin{abstract}
Chitin was prepared from prawn shell waste by a chemical process involving demineralization, deproteinization and decolorization. Chitosan was prepared from chitin by deacetylation. The present study was undertaken to evaluate the influence of deacetylation process during chitosan production on the physiochemical and functional properties of prawn shell chitosan. Four experimental chitosan samples were prepared at ambient temperature with different duration of deacetylation process (i.e. 45, 55, 65 and 72 hrs and their characteristics were evaluated. This study demonstrated that duration of deacetylation affected mostly the degree of deacetylation, solubility and viscosity of the product. Therefore, the process of deacetylation of chitin for conversion to chitosan needs careful control and observation.
\end{abstract}

Key words: Prawn shell, Duration of Deacetylation, Chitosan, Ambient temperature, Physicochemical and Functional properties.

\section{Introduction}

Chitosan is a fiber-like substance derived from chitin, a homopolymer of $ß-(1 \rightarrow 4)$-linked $N$-acetyl-D-glucosamine. Chitin is widely distributed in marine invertebrates, insects, fungi, and yeast (Austin et al., 1981). However, chitin is not present in higher plants and higher animals. Generally, the shell of selected crustacean consists of $30-40 \%$ protein, 30$50 \%$ calcium carbonate and calcium phosphate, and 20-30\% chitin (Knorr 1984). Chitin is widely available from a variety of source among which, the principal source is shellfish waste such as shrimps, crabs, and crawfish (Allan and Hadwiger, 1979). It also exists naturally in a few species of fungi.

In terms of its structure, chitin is associated with proteins and, therefore, high in protein contents. Chitin fibrils are embedded in a matrix of calcium carbonate and phosphate that also contains protein. The matrix is proteinaceous, where the protein is hardened by a tanning process (Muzzarrelli, 1976). Studies of Asford and co-workers (1977) demonstrated that chitin represents $14-27 \%$ and $13-$ $15 \%$ of the dry weight of shrimp and crab processing wastes, respectively. With regard to their chemical structure (Figure 1), chitin and chitosan have a similarity in chemical structure. Chitin is made up of a linear chain of acetylglucosamine groups while chitosan is obtained by removing enough acetyl groups $\left(\mathrm{CH}_{3}-\mathrm{CO}\right)$ from chitin, the molecule and the resultant product is found to be soluble in most diluted acids. The actual difference between chitin and chitosan is the acetyl content of the polymer. Chitosan having a free amino group is the most useful derivative of chitin (No and Meyers, 1992).

Chitosan is a non toxic, biodegradable polymer of high molecular weight, and is very much similar to cellulose, a plant fiber (Figure 1). After cellulose, chitin is the second most abundant natural biopolymer found in nature (No and Meyers, 1989).

However, unlike plant fiber, chitosan possesses unique properties including the ability to form films, optical structural characteristics. Chitosan also possesses a positive ionic charge, which gives it an ability to chemically bind with negatively charged fats, lipids and bile acids (Sandford, 1992). Over the last several years, chitinous polymers, especially chitosan, have received much attention as one of the promising renewable polymeric materials for their extensive applications in the pharmaceutical and biomedical industries for enzyme immobilization and purification, in chemical plants for wastewater treatment, and in food industries for food formulations as binding, gelling, thickening and stabilizing agent (Knorr, 1984; Li, et al., 1992 Prashanth, and Tharanathan, 2007).

\footnotetext{
* Corresponding author: E-mail: nessa1995@yahoo.com
} 
Chitosan is easily obtained from crab especially Dungeness crab (Cancer magister), shrimp particularly the Pacific shrimp (Pandalus borealis), lobster, or crawfish shells (Knorr, 1991). Traditional isolation of chitin from crustacean shell waste consists of three basic steps: demineralization (calcium carbonate and calcium phosphate separation), deproteinization (protein separation), and decolorization (removal of pigments). These three steps are the standard procedure for chitin production (No et al, 1989). The subsequent conversion of chitin to chitosan (deacetylation) is generally achieved by treatment with concentrated sodium hydroxide solution (40-50\%) at $100^{\circ} \mathrm{C}$ or higher temperature to remove some or all of acetyl group from the chitin (No and Meyers, 1995; Galed et. al., 2008). formed the basis of chemical processes for industrial production of chitosan. But most of the reported processes were carried out at $100^{\circ} \mathrm{C}$ or higher temperature with autoclaving (Horton and Lineback, 1965; Domard and Rinadudo, 1983; Prashanth and Tharanathan, 2007; Galed et al., 2008). Therefore, the specific objectives of this work were to develop an optimum condition for production of chitosan from prawn shell.

\section{Materials and Methods}

\section{Prawn shell chitosan production}

Dried Prawn shell waste was obtained from a commercial shrimp shell processor of Khulna. Upon receipt, shells were then further sun dried for a period of 24 hrs or longer until

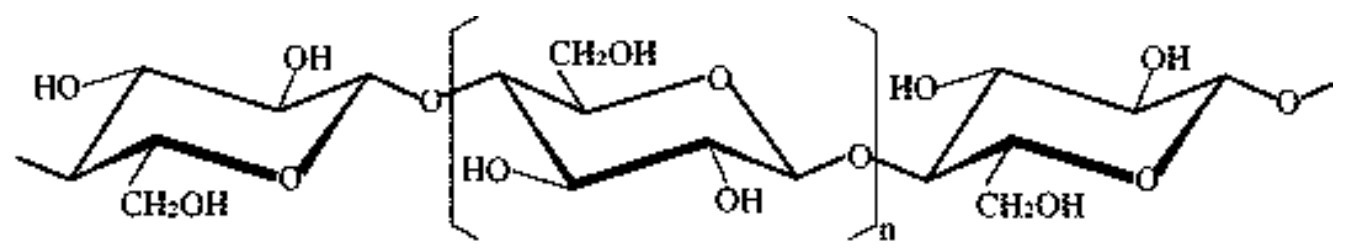

Cellulose

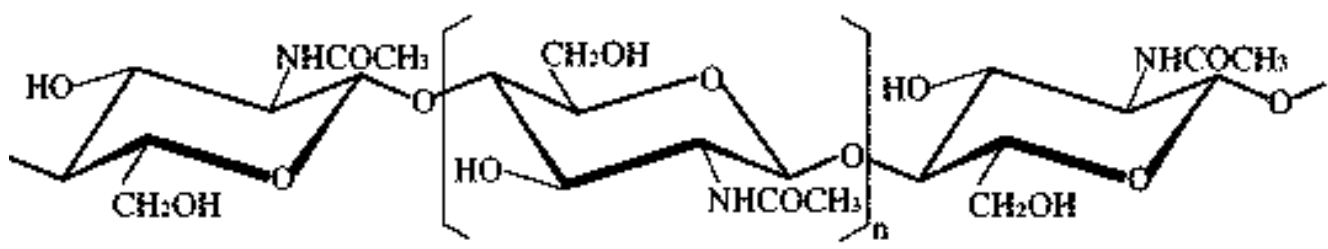

Chitin

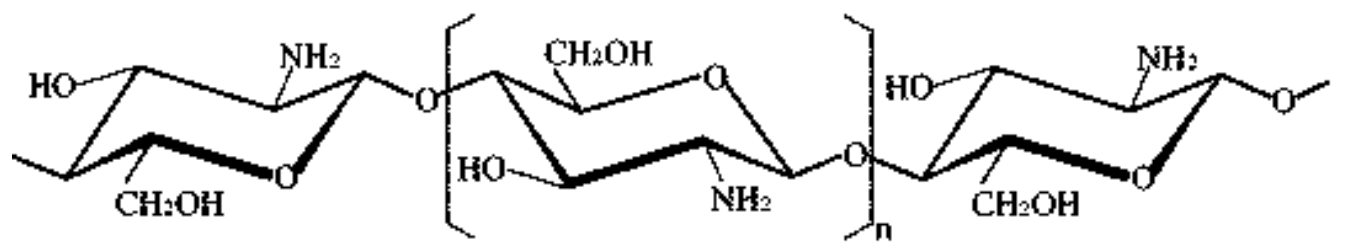

Chitosan

Figure 1: Structure of Cellulose, Chitin and Chitosan

Earlier studies by several authors (Cho et. al., 1998; No et al., 2000) have demonstrated that the physicochemical characteristics of chitosan affect its functional properties, which also differ due to crustacean species and preparation methods. Several procedures have been developed and proposed by many researchers over the years for preparation of chitosan from different crustacean shell wastes. Some of these completely dried. To obtain a uniform size product, the dried shell was ground into course particles through a centrifugal grinding mill. Dried ground shell was placed in opaque plastic bottles and stored at ambient temperature until used. The production of chitosan from prawn shell waste was carried with a modified method of No et. al., (1989). The dried prawn shell $(1 \mathrm{~kg})$ was demineralized with $10 \%$ hydrochloric 
acid at ambient temperature with a solid-to- solvent ratio of $1: 10(\mathrm{w} / \mathrm{v})$, in an acid resistant vessel and stirred for $22 \mathrm{hrs}$. The demineralized shells were deproteinized with $10 \%$ sodium hydroxide solution for $24 \mathrm{hrs}$ at $70^{\circ} \mathrm{C}$ at a solid to solvent ratio of 1:15 (w/v). Samples were then washed with tap water and decolorized with acetone. The samples were then dried under vacuum for 2-3 hrs until the powder was crispy. The resultant product was chitin. Removal of acetyl groups from chitin was achieved by using 60\% concentrated sodium hydroxide solution with a solid to solvent ratio of 1:15 (w/v). Four samples of prawn shell chitosans were prepared. The chemical reactions were carried out at ambient temperature. The duration of deacetylation process was 45 hrs for sample A, 55 hrs for B, 65 hrs for C and 72 hrs for D. The resulting chitosans were washed to neutrality in running tap water, rinsed with distilled water, filtered, and dried at

$65^{\circ} \mathrm{C}$ for 40 hrs in the oven. The prawn shell chitosan thus obtained was white to off white flakes.

\section{Physicochemical and functional properties}

\section{Moisture content}

Moisture content of the prawn shell chitosan was determined by the gravimetric method (Black, 1965).

\section{Nitrogen}

The nitrogen of the prawn chitosan was determined using a microprocessor-based, software-controlled instrument Model-TruSpec CN (Model \# FP-428 Leco Corporation, USA).

\section{Ash}

Ash of the prawn chitosan was calculated according to the standard method \# 923.03 (AOAC, 1990). Three samples of chitosan, each weighting $2.0 \mathrm{~g}$ were placed into three previously ignited, cooled, and tarred crucibles. The samples were heated in a muffle furnace at $600^{\circ} \mathrm{C}$ for $6 \mathrm{hrs}$. The crucibles were allowed to cool in the furnace to less than $200^{\circ} \mathrm{C}$ and then placed into desiccators with a vented top. The crucibles were allowed to cool and then weighed. The amount of ash was noted in each case and the mean value was recorded.

\section{Degree of deacetylation}

Chitosan samples prepared in the form of $\mathrm{KBr}$ disc were studied for the degree of deacetylation (DD). The prepared chitosan $\mathrm{KBr}$ disc were kept in desiccators for 12 hrs and then placed in sealed plates before scanning. The DD of chitosan was established using a FTIR (Fourier Transform Infrared Spectroscopy) instrument (FTIR Model \# 8900, Shimadzu, Koyto Japan) with frequency of 4000-400 $\mathrm{cm}^{-1}$. The DD of the chitosan was calculated using the baseline cited by Khan et. al., 2002. The computation equation for the baseline is given below:

$$
\mathrm{DD}=100-\left[\left(\mathrm{A}_{1655} / \mathrm{A}_{3450}\right) \times 100 / 1.33\right]
$$

where $A_{1655}$ and $A_{3450}$ were the absorbance at $1655 \mathrm{~cm}^{-1}$ of the amide-I band as a measure of the $\mathrm{N}$-acetyl group content and $3450 \mathrm{~cm}^{-1}$ of the hydroxyl band as an internal standard to correct for disc thickness. The factor '1.33' denoted the value of the ratio of $A_{1655} / A_{3450}$ for fully $\mathrm{N}$-acetylated chitosan.

\section{Viscosity}

Viscosity of chitosan was determined with a Brookfield viscometer (Model DV-II + Brookfield Engineering Laboratories, Inc., USA.). A 1\% solution of chitosan was prepared in $1 \%$ acetic acid and used in the experiment. Measurement was made in duplicate using No. 27 spindle at $50 \mathrm{rpm}$ at $25^{\circ} \mathrm{C}$ and the results were reported in centipoises (cPs).

\section{Solubility}

Prawn chitosan sample $0.1 \mathrm{~g}$ was placed into a centrifuge tube (known weight) and $10 \mathrm{ml}$ of $1 \%$ acetic acid was added and left for $30 \mathrm{~min}$. The mixture was then centrifuged (Model \# 5100, Kubita corporation, Tokyo, Japan) at 10,000 rpm for $10 \mathrm{~min}$. The supernatant liquid was decanted. The un-dissolved particles were washed with distilled water (25ml) then centrifuged at 10,000 rpm. The supernatant liquid was removed and the un-dissolved pellets dried at $60^{\circ} \mathrm{C}$ for 24hr. Finally, the amount of the residue was weighted and the percentage of solubility was determined.

\section{Water Binding Capacity (WBC)}

WBC of chitosan was measured using a modified method of Knorr, (1982). WBC was initially carried out by weighing a centrifuge tube containing $0.5 \mathrm{~g}$ of the sample, adding $10 \mathrm{ml}$ of water, and mixing on a vortex mixer for $1 \mathrm{~min}$ to disperse the sample. The contents were left at ambient temperature 
for 30 min with intermittent shaking for 5 s in every $10 \mathrm{~min}$ and centrifuged at 3,500 rpm for $25 \mathrm{~min}$. After the supernatant water was decanted of the tube was weighed again. WBC was calculated as follows: WBC $(\%)=$ [water bound (g)/ initial sample weight (g)]x 100. All experiments were triplicated.

\section{Fat Binding Capacity (FBC)}

FBC of chitosan was measured with three types of oils e.g. soybean, corn \& sunflower using a modified method of Knorr, (1982). FBC was initially carried out by weighing a centrifuge tube containing $0.5 \mathrm{~g}$ of sample, adding $10 \mathrm{ml}$ of one of the oils and mixing on a vortex mixer for 1 min to disperse the sample. The contents were left at ambient temperature for 30 min with shaking for $5 \mathrm{~s}$ in every10 min and centrifuged at 3,500 rpm for $25 \mathrm{~min}$. After the supernatant oil was decanted off the tube was weighed again. Similar experiments were carried out with corn and sunflower oils. FBC was calculated as follows: FBC $(\%)=[$ fat bound $(\mathrm{g}) /$ initial sample weight (g)] x 100. All experiments were carried out in triplicate.

\section{Statistical analysis}

All experiments were carried out in triplicate, Average values and standard deviations were reported. Mean separations were analyzed using the ANOVA and Tukey's studentized range tests at $\alpha=0.05$.

\section{Results and Discussion}

Yield: Yield was calculated as the dry weight of chitin obtained from $1 \mathrm{~kg}$ of dried prawn shell powder. The yield of chitin was $20 \%$ and chitosan ranged from $16.4-19.6 \%$. The highest yields were obtained from sample A (19.6\%), followed by C (18.5\%), D (17.7\%), and B (16.4\%). Results are shown in Table I. Brzeski (1982) reported about 14\% yield of chitosan from krill and $18.6 \%$ from prawn waste (Alimuniar and Zainuddin, 1992). The \% yield of chitosan obtained (16.4-19.6\%, Table I) is lower than that reported in the literature (approximately 23\%) of chitin) (No and Meyers, 1989). This is perhaps due to loss of sample weight from excessive removal of acetyl groups from the polymer during deacetylation (i.e. the conversion of chitin to chitosan).

\section{Moisture content}

Results of the moisture, nitrogen and ash content of chitosan samples are presented in Table1. Chitosan is hygroscopic in nature (Khan et. al., 2002), hence it can be affected by moisture absorption during storage. According to Li et. al., (1992), commercial chitosan product contains less than 5\% moisture. The prawn shell chitosan samples had a moisture content ranging from $0.3 \%$ to $0.4 \%$.

\section{Nitrogen content}

The nitrogen content of the prawn shell chitosan samples varied between $7.91 \%$ and $8.33 \%$ and showed no significant differences $(p>0.05)$ but the values were slightly higher than that (7.06\% to $7.97 \%$ ) reported by No and Meyers (1995) for chitosan from crab and shrimp shell. This is probably due to the presence of protein residues as mentioned by Rutherford and Austin (1978). Protein is bound by covalent bonds forming stable complex with chitin and chitosan. Thus, it is very difficult to achieve $100 \%$ deproteinization. Even with complete deproteination, nitrogen of the free amino $\left(-\mathrm{NH}_{2}\right)$ group can not be estimated.

Ash

Ash measurement is an indicator of the effectiveness of the demineralization step for removal of calcium carbonate. Demineralization resulted in products having 31 - 36\% ash (Bough et. al., 1978). The ash content in chitosan is an

Table I: Proximate Analysis of Prawn Shell Chitosans (dry weight basis)

\begin{tabular}{l|c|c|c|c}
\hline Sample & Yield (\%) & Moisture (\%) & Nitrogen (\%) & Ash (\%) \\
\hline A & 19.6 & $0.45(0.35) a^{*}$ & $8.33(0.34) a^{*}$ & $0.19(0.27) a^{*}$ \\
B & 16.4 & $0.34(0.33) \mathrm{a}$ & $8.19(0.43) \mathrm{a}$ & $0.23(0.59) \mathrm{a}$ \\
C & 18.5 & $0.43(0.45) \mathrm{a}$ & $8.11(0.62) \mathrm{a}$ & $0.21(0.56) \mathrm{a}$ \\
D & 17.7 & $0.44(0.35) \mathrm{a}$ & $7.91(0.56) \mathrm{a}$ & $0.24(0.78) \mathrm{a}$ \\
\hline
\end{tabular}

*Numbers in parentheses are standard deviations $( \pm)$. Means were not significantly $(\mathrm{p}<0.05)$ different as shown with similar letters in each column. 
important parameter. Some residual ash of chitosans may affect their solubility, consequently contributing to lower viscosity, or can affect other more important characteristics of the final product. A high quality grade of chitosan should have less than $1 \%$ of ash content (No and Meyers 1995). An ash content of less than 1\% from crab chitosans has been reported by No and Meyers (1995). Table I also shows the ash content of prawn shell chitosans with a range of $0.19 \%$ to $0.24 \%$.

\section{Degree of deacetylation}

The degree of deacetylation (DD) of our prawn shell chitosan samples ranged from $45 \%$ to $75 \%$ (Table II). According to No and Meyers (1995), DD of chitosan ranges from $56 \%$ to $99 \%$ with an average of $80 \%$. Sample C (75\%) had the highest DD, followed by D, B and A (74\%, 71\%, and $45 \%$, respectively).

As in the Table II, sample-A had a very low solubility and viscosity which may be due to incomplete degree of deacetylation. Therefore, in comparison with sample B, and D, sample C gave lower viscosity (136.9 cP) and higher DD (75\%) value which are very important characteristics of chitosan. The medical and pharmaceutical applications of chitosan as antitumor, hemostatic, hypocholesterolemic, antimicrobial, and antioxidant depends mostly on its DD and solubility (Muzzarelli and Muzzarelli, 2005; Jian et. al., 2008). However, we expected that samples B, C and D should have higher DD they have higher solubility but the value observed was lower than expected. According to Kassai et. al. (2008), the IR spectroscopic method is commonly used for the estimation of chitosan DD values for its advantages: it is relatively fast and does not require dissolution of the chitosan sample in an aqueous solvent. However, its disadvantage is that utilizing different baselines to calculate DD values would inevitably contribute to variations upto $47 \%$ in DD values. Thus, accurate determination of the degree of deacetylation of chitosan is needed. DD values are not only highly dependent on the source and method of purification (No et. al., 1989) but also on the type of analytical methods employed, sample preparation, and type of instrument used, and other conditions may influence the analysis of DD (Khan et. al., 2002).

\section{Viscosity}

The viscosity of chitosan solutions were reported in the literature generally ranges from 60 to $780 \mathrm{cP}$ (Alimuniar and Zainuddin, 1992). These ranges of viscosity were also observed by Cho et. al. (1998) with five commercially available chitosans. The observed figures on viscosity solubility and degree of deacetylation of our prawn shell chitosans are shown in Table II.

Table II: Viscosity, Solubility, and Degree of deacetylation of Prawn Shell Chitosans

\begin{tabular}{l|c|c|c}
\hline Sample & $\begin{array}{c}\text { Viscosity } \\
\text { (cP) }\end{array}$ & $\begin{array}{c}\text { Solubility } \\
(\%)\end{array}$ & $\begin{array}{c}\text { Degree of } \\
\text { Deacetylation (\%) }\end{array}$ \\
\hline A & $88.2(6.77) * a$ & $44.3(0.91) \mathrm{a}$ & 45 \\
B & $173.4(5.26) \mathrm{c}$ & $96.01(1.45) \mathrm{b}$ & 71 \\
C & $136.9(5.09) \mathrm{b}$ & $97.2(0.99) \mathrm{b}$ & 75 \\
D & $134.19(4.69) \mathrm{b}$ & $97.06(1.56) \mathrm{b}$ & 73 \\
\hline
\end{tabular}

*Numbers in parentheses are standard deviations ( \pm ). Means with different letters in each column are significantly different $(\mathrm{p}<0.05)$.

Bough et. al. (1978) stated that viscosity of chitosans varied considerably from 60 to $5,110 \mathrm{cP}$ depending on the species. Our prawn shell samples had viscosity ranging from 88.2 to $173.4 \mathrm{cP}$. A had the lowest viscosity $(88.2 \mathrm{cP})$ comparable to that of other samples as their lower solubility may be due to incomplete deacetylation of chitin. Whereas B had a high viscosity (173.4 cP) (Table II). Sample D showed lower viscosity than sample $\mathrm{C}$, though the difference was not significant. It may be due to longer duration of deacetylation which might degrade chitosan. It seemed that duration of deacetylation is an important step which might affect the quality of the product. There are some other factors affecting viscosity during the production of chitosan such as the molecular weight, concentration, ionic strength, $\mathrm{pH}$, and temperature, etc (Moorjani et. al., 1975; Bough et. al., 1978). The chitosan with lower viscosity have a number of advantages over high viscous chitosan for use in food and pharmaceutical industry.

\section{Solubility}

Three prawn shell chitosan samples B, C, D were found to have excellent solubility ranging from 96.01 to $97.2 \%$ with no significant difference (Table II), except sample A which showed comparatively lower solubility (44.3\%) and this may 
be due to lower degree of deacetylation (DD). Brine and Austin (1981) noted that lower solubility values suggested incomplete removal of protein and acetyl group. Since solubility of chitosan depends on the removal of acetyl group from chitin, therefore the lower DD value and the presence of protein contaminants remaining in the sample during the process of analysis could adversely interfere with the results.

\section{Water Binding Capacity (WBC)}

Water binding capacities of prawn shell chitosans are shown in Table III. WBC of the samples B, C \& D varied from $738.3 \%$ to $748.4 \%$. Sample A had a lower WBC (345.6 \%) than that of other sample it may be due to lower $\mathrm{DD}$ value. There were no significant differences in WBC between $\mathrm{B}, \mathrm{C}$ and $\mathrm{D}$. These values may be compared with those reported by Cho et, al., (1998) where WBC for chitosans ranged from $458 \%$ to $805 \%$ for five commercial chitosans from shrimp and crab shell.

Table III. Water and Fat Binding Capacity of Prawn Shell Chitosans

\begin{tabular}{l|c|c|c|c}
\hline \multirow{2}{*}{ Sample } & WBC (\%) & \multicolumn{3}{|c}{ Fat Binding Capacity (\%) } \\
\cline { 2 - 5 } & & Soybean & Corn & $351.7(6.4) \mathrm{a}$ \\
$\mathrm{A}$ & $345.6(9.9)^{*} \mathrm{a}$ & $348.7(7.8) \mathrm{a}$ & $335.5(5.5) \mathrm{a}$ & $588.8(8.6) \mathrm{b}$ \\
$\mathrm{B}$ & $741.2(6.1) \mathrm{b}$ & $565.2(5.3) \mathrm{b}$ & $579.8(8.7) \mathrm{b}$ & $579.9(4.2) \mathrm{b}$ \\
C & $748.4(4.9) \mathrm{b}$ & $565.5(8.9) \mathrm{b}$ & $589.6(8.7) \mathrm{b}$ & $568.9(6.9) \mathrm{b}$ \\
D & $738.3(5.05) \mathrm{b}$ & $568.1(7.5) \mathrm{b}$ & $578.7(6.9) \mathrm{b}$ & \\
\hline
\end{tabular}

*Numbers in parentheses are standard deviations $( \pm)$. Means with different letters in each column are significantly different $(\mathrm{p}<0.05)$.

\section{Fat Binding Capacity (FBC)}

Fat binding capacity (FBC) of four prawn shell chitosans was measured using three types of oils soybean, corn, and sunflower oil. The results are shown in Table III. FBC differed among chitosan products, ranging from 335.5\% to $589.6 \%$. But there were no statistical significance of FBC amongst the samples $\mathrm{B}, \mathrm{C}$ and $\mathrm{D}$ with different oils. The lowest FBC values for the sample A indicates incomplete deacetylation, It thus seems complete deacetylation facilitates oil binding capacity of chitosan. Moorjani (1975) advocated that changing the sequence of steps, i.e when demineralization is conducted prior to deproteinization and finally deacetylation, results in an increase in FBC than when deproteinization is conducted prior to demineralization and finally deacetylation. Regardless of the type of vegetable oils, the three prepared prawn shell chitosan samples (B, C
\& D) showed desirable FBC which is in agreement with those (314 to $535 \%$ with an average of $40 \%$ ) reported by No et, al. (2000).

\section{Conclusion}

The quality and physicochemical properties of chitosan vary widely with crustacean species and methods of preparation. Most of the literature reported high temperature method to have been used for production of chitosan. On these background this research study was taken up to present a process for the production of chitin and chitosan from prawn shell at ambient temperature, and this may help to develop small industry without consumption of high energy. This study has also been shown that the period of deacetylation process affects the quality of the products. For instance, shorter reaction period resulted in decrease in solubility, lower water/fat binding capacity and incomplete degree of deacetylation. Longer deacetylation periods produced product, having 
AOAC. (1990). Official Methods of Analysis, 15th ed.; Association of Official Analytical Chemists: Washington, DC, 1990.

Ashford N. A., Hattis D. and Murray A. E. (1977). Industrial prospects for chitin and protein from shellfish wastes; MIT Sea Grant Report MISG 77-3:MIT: Cambridge, MA.

Austin P. R., Brine C. J., Castle J. E. and Zikakis J. P. (1981). Chitin: New facets of research. Science. 212:749-753.

Black C. A. ed. (1965). Methods of Soil Analysis: Part I physical and mineralogical properties. American Society of Agronomy. Madison, Wisconsin. pp. 671698.

Bough W. A., Salter W. L., Wu A. C. M. and Perkins B.E. (1978) Influence of manufacturing variables on the characteristics and effectiveness of chitosan products.

1. Chemical composition, viscosity, and molecular weight distribution of chitosan products. Biotechnol. Bioeng. 20:1931.

Brine C. J. and Austin P. R. (1981). Chitin variability with species and method of preparation. Comp. Biochem. Physiol. 69B: 283-286.

Brzeski M. M. (1982). Concept of chitin/chitosan isolation from Antarctic Krill (Euphausia superba) shells on a technique scale. In Proceedings of the Second International Conference on Chitin and Chitosan; S. Hirano and S. Tokura (Ed.), p.15. The Japan Society of Chitin and Chitosan, Sapporo, Japan.

Cho Y. I., No H. K. and Meyers S. P. (1998). Physicochemical Characteristics and Functional Properties of various Commercial Chitin and Chitosan Products. J. Agric. Food Chem. 46(9): 3839-3843.

Domard A. and Rinadudo M. (1983). Preparation and characterization of fully deacetylated chitosan. J. Biol. Macromol. 5: 49-52.

Galed G., Diaz E. and Heras A. (2008). Conditions of Ndeacetylation on chitosan production from alpha chitin. Nat. Prod. Commun. 3(4): 543-50.
Horton D. and Lineback D. R. (1965). N-deacetylation, chitodan from chitin. In: Whistler RL, Wolfson ML, Eds. Methods in Carbohydrate Chemistry. New York: Academic Press. pp.403.

Jian Y., Feng T., Zheng W., Qing W., Yan-Jun Z. and ShiQian C. (2008). Effect of Chitosan Molecular Weight and Deacetylation Degree on Hemostasis. J Biomed. Mater. Res. 84B: 131-7.

Kassai M. A. (2008). Review of several reported procedures to determine the degree of $\mathrm{N}$-acetylation for chitin and chitosan using infrared spectroscopy. Carbohydr Polym. 71: 497-508.

Khan T., Peh K. and Ch'ng H. S. (2002). Reporting degree of deacetylation values of chitosan: the influence of analytical methods. J Pharm Pharmaceut Sci. 5(3):205-212.

Knorr D. (1982). Functional properties of chitin and chitosan. J. Food Sci. 47: 593-595.

Knorr D. (1984). Use of chitinous polymers in food- A challenge for food research and development. Food Technol. 38(1): 85-97.

Knorr D. (1991). Recovery and Utilization of Chitin and Chitosan in Food Processing Waste Management. Food Technol.. 114-122.

Li Q., Dunn E. T., Grandmaison E. W. and Goosen M. F. A. (1992). Applications and properties of chitosan. $J$. Bioactive and Compatible Polym. 7: 370-397.

Moorjani M. N., Achutha V. and Khasim D. I. (1975). Parameterss affecting the viscosity of chitosan from prawn waste. J. Food Sci. Technol., 12:187-189.

Muzzarelli R. A. A. (1976). Chitin; Pergamom press, Oxford.

Muzzarelli R. A. A. and Muzzarelli C. (2005). Chitosan chemistry: Relevance to the biomedical sciences. Adv Polym. Sci. 186: 151-209.

No H. K., Meyers S. P. and Lee K. S. (1989). Isolation and Characterization of Chitin from Crawfish Shell Waste. J. Agric. Food Chem. 37(3):575-579. 
No H. K. and Meyers S. P. (1989). Crawfish Chitosan as a Coagulant in Recovery of Organic Compounds from Seafood Processing Streams. J. Agric. Food Chem. 37(3): 580-583.

No H. K. and Meyers S. P. (1992). Utilization of Crawfish Processing Wastes as Carotenoids, Chitin, and Chitosan Souces. J. Korean Soc. Food Nutr. 21:319-326.

No H. K. and Meyers S. P. (1995). Preparation and Characterization of Chitin and Chitosan-A Review. J. Aquatic Food Prod. Technol.. 4(2):27-52.

No H. K., Lee K. S. and Meyers S. P. (2000). Correlation Between Physicochemical Characteristics and Binding Capacities of Chitosan Products. J. Food Sci. 65(7):1134-1137.
Prashanth R. and Tharanathan R. (2007). Chitin/chitosan: modifications and their unlimited application potentialan overview. Trends Food Sci. Tech. 18: 117-31.

Rutherford F. A. and Austin P. R. (1978). Marine chitin properties and solvents. In Proceedings of the First International Conference on Chitin /Chitosan; Muzzarrelli, R.A.A., Austin, P.R., Eds. MIT Sea Grant Program, Cambridge, MA. pp.182-192;

Sandford P. A. (1992). High purity chitosan and alginate: Preparation, analysis, and applications. Front. Carbohydr. Res. 2: 250-269.

Received : October 25, 2009;

Accepted : August 24, 2010 